This item was submitted to Loughborough's Research Repository by the author.

Items in Figshare are protected by copyright, with all rights reserved, unless otherwise indicated.

\title{
Parametric study of asymmetric side tapering in constant cross wind conditions
}

PLEASE CITE THE PUBLISHED VERSION

https://doi.org/10.4271/2018-01-0718

PUBLISHER

(C) SAE International

VERSION

AM (Accepted Manuscript)

\section{PUBLISHER STATEMENT}

This work is made available according to the conditions of the Creative Commons Attribution-NonCommercialNoDerivatives 4.0 International (CC BY-NC-ND 4.0) licence. Full details of this licence are available at: https://creativecommons.org/licenses/by-nc-nd/4.0/

\section{LICENCE}

CC BY-NC-ND 4.0

\section{REPOSITORY RECORD}

Varney, Max, Martin A. Passmore, and Adrian P. Gaylard. 2018. "Parametric Study of Asymmetric Side Tapering in Constant Cross Wind Conditions". figshare. https://hdl.handle.net/2134/32858. 


\title{
Parametric Study of Asymmetric Side Tapering in Constant Cross Wind Conditions
}

\author{
Author, co-author (Do NOT enter this information. It will be pulled from participant tab in \\ MyTechZone) \\ Affiliation (Do NOT enter this information. It will be pulled from participant tab in MyTechZone)
}

\begin{abstract}
Sports Utility Vehicles (SUVs) often have blunt rear end geometries for design and practicality, which is not typically aerodynamic. Drag can be reduced with a number of passive and active methods, which are generally prioritised at zero yaw, which is not entirely representative of the "on road" environment. As such, to combine a visually square geometry (at rest) with optimal drag reductions at non-zero yaw, an adaptive system that applies vertical side edge tapers independently is tested statically.

A parametric study has been undertaken in Loughborough University's Large Wind Tunnel with the $1 / 4$ scale Windsor Model. The aerodynamic effect of implementing asymmetric side tapering has been assessed for a range of yaw angles $\left(0^{\circ}, \pm \mathbf{2 .} \mathbf{5}^{\circ}, \pm \mathbf{5}^{\circ}\right.$ and $\mathbf{\pm 1 0 ^ { \circ }}$ ) on the force and moment coefficients. This adaptive system reduced drag at every non-zero yaw angle tested, from the simplest geometry (full body taper without wheels) to the most complex geometry (upper body taper with wheels) with varying levels of success; providing additional drag reductions from $3 \%$ to $125 \%$. The system also shows potential to beneficially modify the cross wind stability of the geometry.
\end{abstract}

\section{Introduction}

Aerodynamic drag is an increasing concern for vehicle manufacturers due to its impact on a number of performance metrics, particularly fuel economy and emissions and the range of battery electric vehicles. Hence, finding new methods for reducing drag is becoming more important, and this is particularly the case for SUVs that typically have blunt rear end geometry with up to $30 \%$ of the aerodynamic drag being attributed to the rear surfaces [1]. This rear end drag is driven by flow separations from the trailing perimeter of the vehicle, generating shear layer bounding recirculating flows, which lower the pressure on the base of the vehicle.

Studies to reduce the drag by affecting the recirculating region and increasing the base pressure include both passive and active methods. Typical passive methods include side tapering [2-4], roof tapering [3-8] and passive base ventilation [4]. Active methods include active base ventilation [9], blowing [10-12] and rotating edges [13], with all active methods showing drag reductions but requiring an energy input, that at least partially offsets any gains and that are difficult to scale up to a full sized geometry.
Whether passive or active all such methods alter the shear layers around separation reducing the drag contribution of the base region of the vehicle. They also typically exhibit an optimum condition whereby the reduction in drag contribution of the base is not offset by the newly introduced drag contributions, such as slant drag [2-4,7] or device drag $[5,14]$.

Pavia et al. [2] and Perry et al. [3] both consider high aspect ratio side edge tapers (aspect ratio of 6.42) on a Windsor geometry and show the optimum at $0^{\circ}$ yaw to be at $12^{\circ}$ for both overall drag and the reduction in base pressure drag contribution. Taper angles larger than this showed a rise in the pressure drag contribution from the tapered surface with a reduction in the drag on the base of the geometry or, if the taper is stalled, a return to a base pressure drag contribution similar to the $0^{\circ}$ taper but a larger overall drag due to the suction over the tapered surfaces.

Howell et al. [15] applied tapering to the upper $56 \%$ of a Windsor geometry on both the roof and the side edges. The junction between the upper body taper and the un-tapered lower body (the shoulder) produced a streamwise vortex that generates downwash.

Varney et al. [4] applied side edge tapering to a Generic SUV geometry at a small aspect ratio $(\sim 1.5)$ on only the upper $40 \%$ of the geometry, producing the same shoulder junction as Howell et al. [15]. This geometry produced a drag optimum at $15^{\circ}$ but the study did not report the base pressure drag separately. When considering the base pressure distributions, on the single instance discussed, the indication is that the wake switched from an up-wash dominated wake to a downwash dominated wake with the introduction of the $15^{\circ}$ taper, showing it to be a non-trivial modification. The justification for this geometry was improved realism, as practical vehicles generally cannot accommodate a full height body side trailing edge taper because of the requirement to cover the rear wheels.

The literature mainly focusses on drag reduction at zero degree yaw and with low turbulence onset flows, which neglects a number of potentially significant on-road effects [16-19]. However, Englar et al. [11] and Englar [12] present work on streamlined bodies as well as heavy goods vehicles at a large range of yaw angles using jets of air at various locations close to, or around, the rear of the geometry to control all of the force and moment coefficients. This system showed a potential to significantly modify the coefficients associated with cross wind stability (side force, yawing moment and rolling moment) with no moving components on the exterior of the vehicle, although the system involved significant internal complexity. 
An adaptive system has been implemented by de la Cruz et al. [20] with vertical flaps added to an Ahmed body and applied asynchronously under constant cross winds. This work showed that, depending on the yaw angle, the asymmetric base flap application was between $40 \%$ and $70 \%$ better than the best symmetric flap configuration. The optimum geometries in this instance show that the flaps work to re-symmetrise the wake, with a large angle on the windward (left hand) side (at positive yaw) and a negative (protruding past the vehicle side) angle on the leeward (right hand) side.

The work reported in this paper demonstrates the potential of asymmetric side edge tapering for drag reduction when a vehicle is subject to an onset flow with a realistic yaw angle distribution. This is aimed at defining the potential of an adaptive system that has the benefit of relatively small energy input (not demonstrated here) along with the flexibility of numerous passive configurations allowing an optimum to be tracked under a wide range of cross wind conditions.

\section{Experimental Set Up}

\section{The Facilities}

All testing was carried out in the Loughborough University Large Wind Tunnel (Figure 1). This tunnel is an open return, closed working section design capable of flow speeds up to $45 \mathrm{~m} / \mathrm{s}$ with a turbulence intensity of $0.2 \%$, a flow uniformity of $\pm 0.4 \%$ and a cross sectional area of $2.5 \mathrm{~m}^{2}$ [21]

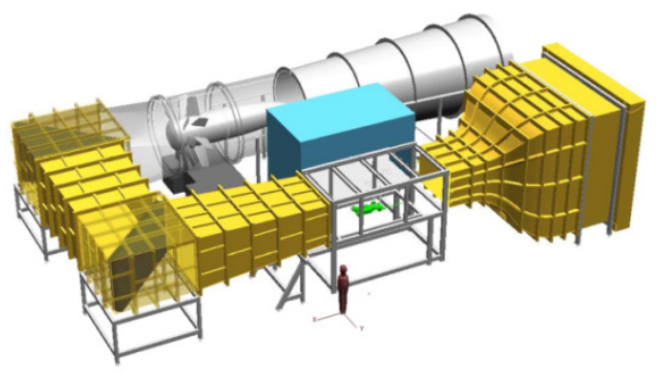

Figure 1. The Loughborough University Wind Tunnel [21]

\section{The Model}

The model used here is a variant on the $1 / 4$ scale Windsor geometry, modified to accept removable wheels, with blanks inserted in place of the wheels if required (Figure 2). This model has a blockage ratio of $4.5 \%$ or $4.7 \%$ for the no wheels and wheels instances respectively at zero yaw and $6.2 \%$ and $6.7 \%$ at $10^{\circ}$ yaw. It was tested at a nondimensional ground clearance of 0.17 (defined as the ground clearance divided by the model body height). All forward facing radii are $50 \mathrm{~mm}$ to prevent separation around the front of the model; all other longitudinal and lateral edges are sharp. The geometries tested are made of either dimensionally stable model board or 3D printed from a rigid opaque material.

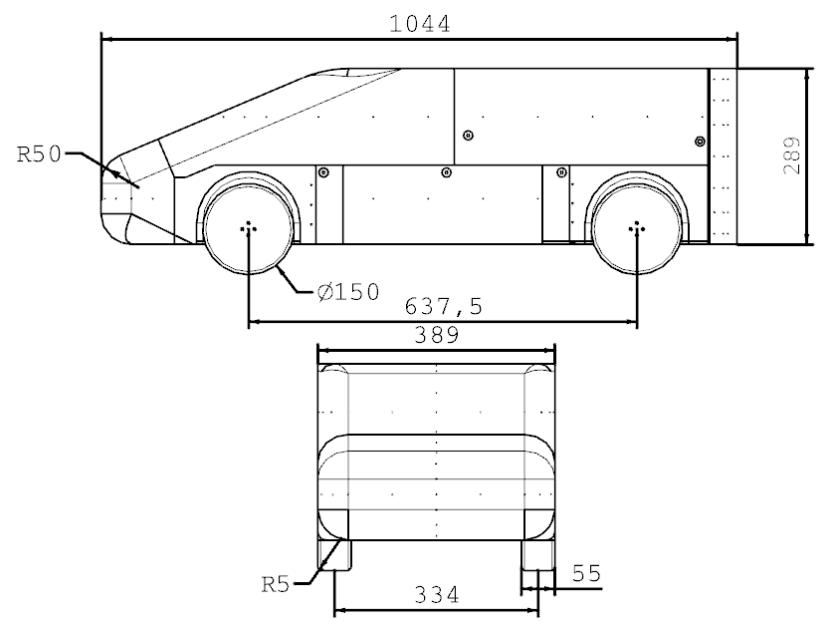

Figure 2. Windsor Geometry

The principal dimensions of this variant of the Windsor geometry are: $1040 \mathrm{~mm}$ (length), $289 \mathrm{~mm}$ (height), $389 \mathrm{~mm}$ (width); with a $334 \mathrm{~mm}$ track and a $637.5 \mathrm{~mm}$ wheelbase.

The coordinate system defined by SAE J1594 [22] is used throughout this work, with the origin located at mid-wheelbase, mid-track and on the ground. The model is supported by four, $8 \mathrm{~mm}$ diameter pins protruding into the working section, on which the model is fastened, these are placed on either side of the model just behind the front wheels and just in front of the rear wheels to minimise the impact on the general flow, no drag tare for the pin protrusion has been included. The wheels have $\sim 4 \mathrm{~mm}$ ground clearance due to a recessed floor panel that maintains a non-dimensional ride height of 0.17 .

The side edge tapers used here have a length of $45 \mathrm{~mm}(15.5 \%$ of the base height) resulting in an aspect ratio of 6.4 , with angles of $0^{\circ}$ to $24^{\circ}$ in steps of $4^{\circ}$ (Figure 3 ) with a sharp leading edge. These are applied individually to the geometry on both the left (windward) and right (leeward) hand side to produce the asymmetric side edge taper angles (Figure 4).
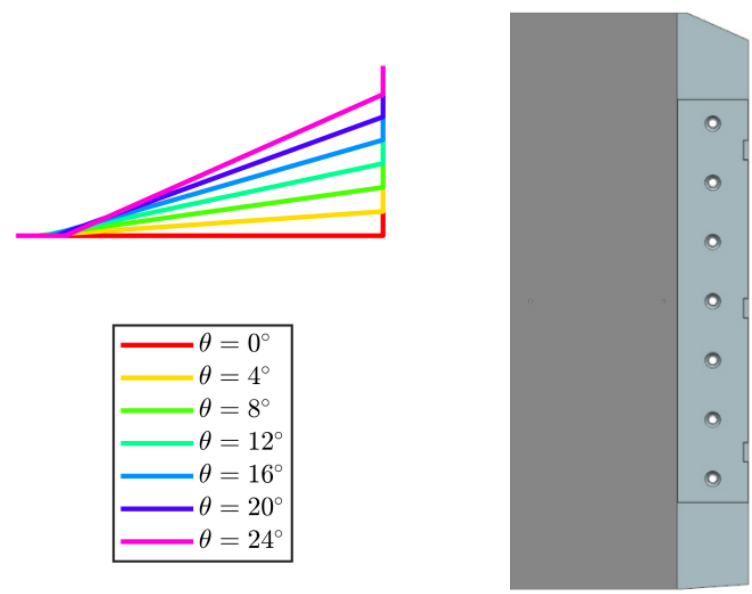

Figure 3. Geometric Representation of Taper Values
Figure 4. Example of Asymmetric Tapering with $\theta_{\text {wind }}=4^{\circ}$ and $\theta_{\text {lee }}=24^{\circ}$


The asymmetric trailing edge tapers have been tested on the Windsor model in a number of configurations:

- Without wheels (Figure 5a)

- With wheels (Figure 5b)

- $\quad$ Full height taper (Figure 5a)

- Upper taper (Figure 5b) i.e. taper on the upper $50 \%$ of the body trailing edge (with the lower 50\% remaining an effective $0^{\circ}$ taper)

- A single geometry with only a lower body taper (with the upper $50 \%$ of the geometry remaining an effect $0^{\circ}$ taper) as this is not deemed a realistic or representative geometry.

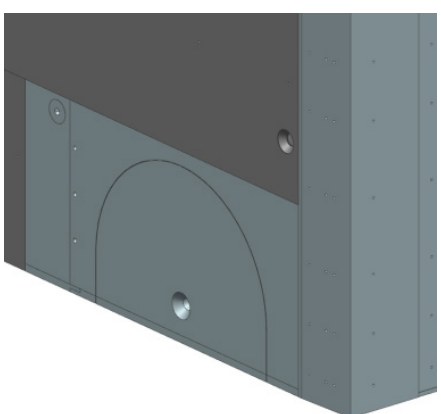

(a) Windsor Body without Wheels and with a $100 \%$ Span Taper

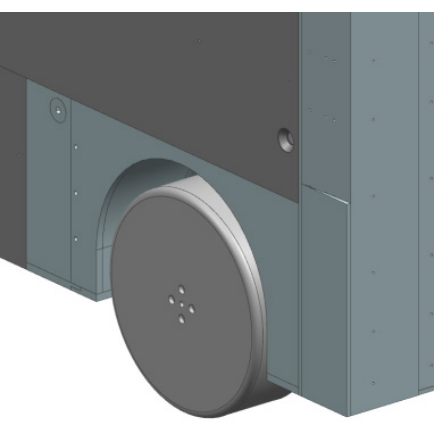

(b) Windsor Body with Wheel and $50 \%$ Span Taper
For consistency the $0^{\circ}$ position was defined as the yaw angle providing the most symmetric base pressure distribution with the $12^{\circ}$ symmetric taper. This was determined independently for both the wheel and no wheel configurations, providing each with their individual $\Psi=0^{\circ}$ position. In the work presented here this resulted in $\Psi_{0}=-0.3^{\circ}$ for no wheels and $\Psi_{0}=0.9^{\circ}$ for with wheels.

The measurement uncertainty was assessed by calculating $95 \%$ confidence intervals of each coefficient using Equation 4 [24]; where $\sigma$ is the standard deviation of the measurement and $N$ is the number of samples taken. The maximum resulting uncertainty from these calculations have been rounded to 3 decimal places and presented in Table 1. This is normalizing the differences between the geometries and the fluctuations throughout all geometries.

$$
95 \% \text { confidence interval }= \pm 1.96 * \frac{\sigma}{\sqrt{N}}
$$

$\sigma-$ Standard Deviation, $N$ - Sample Length

Table 1. Maximum Confidence Interval at 95\% for Each Coefficient

\begin{tabular}{|c|c|c|c|c|c|}
\hline$C_{D}$ & $C_{Y}$ & $C_{L}$ & $C_{M X}$ & $C_{M Y}$ & $C_{M Z}$ \\
\hline \pm 0.001 & \pm 0.002 & \pm 0.001 & \pm 0.003 & \pm 0.002 & \pm 0.002 \\
\hline
\end{tabular}

\section{Results and Discussion}

\section{Symmetric Tapering}

All measurements were taken with an onset flow velocity
(giving a length based Reynolds number of $2.7 \times 10^{6}$ ) at $\Psi=0^{\circ}, \pm 2.5^{\circ}, \pm 5^{\circ}$ and $\pm 10^{\circ}$ yaw (where $\Psi$ is the value of yaw in degrees). Balance forces were sampled at $300 \mathrm{~Hz}$ for 300 seconds and averaged during post processing.

All coefficient calculations use a corrected value for the velocity estimated using a continuity correction seen in Equation 2 [23], no additional corrections have been implemented for the increased blockage with yaw.

$$
v_{\text {corrected }}=\frac{v \cdot A_{t}}{A_{t}-A_{m}}
$$

$\mathrm{A}_{\mathrm{t}}-$ Tunnel Area $\left(\mathrm{m}^{2}\right), \mathrm{A}_{\mathrm{m}}-$ Model Area $\left(\mathrm{m}^{2}\right), \mathrm{v}-\operatorname{Velocity}(\mathrm{m} / \mathrm{s})$

The force and moment coefficient equations can be seen in Equations 3-5, along with the equation for a cycle averaged drag calculation $\left(C_{D W C}\right)$ proposed by Howell et al. [19] and based on the WLTC. The subscripts represent the yaw value at which the drag coefficient is measured. As $\Psi=15^{\circ}$ accounts for less than $1 \%$ of the calculation it is neglected in the following analysis.

$$
\begin{aligned}
& C_{\text {force }}=\frac{\text { Force }}{\frac{1}{2} \rho A_{m} v^{2}} \quad \text { (3) } \quad C_{\text {moment }}=\frac{\text { Moment }}{\frac{1}{2} \rho A_{m} v^{2} L_{w b}} \\
& C_{D W C}=0.53 C_{D 0}+0.345 C_{D 5}+0.13 C_{D 10}+0.007 C_{D 15} \\
& \rho-\text { Air Density }\left(\mathrm{kg} / \mathrm{m}^{3}\right), L_{w b}-\text { Length of the Wheelbase }(\mathrm{m})
\end{aligned}
$$

Page 3 of 9
The results for all symmetric taper angles at $\Psi=0^{\circ}$ are presented in Figure 6; showing (a) $\Delta C_{D}$, (b) $\Delta C_{D W C}$ (calculated with Equation 5) and (c) $\Delta C_{L}$ relative to their appropriate baselines. The abbreviations $N W$ and $W W$ stand for No Wheels and With Wheels.

The optimum configuration with no wheels and a full height taper falls between $8^{\circ}$ and $12^{\circ}$ with both showing a reduction of $\Delta \mathrm{C}_{\mathrm{D}}=$ -0.020 . This optimum is consistent with that determined by Perry et al. [3], using the same facility, who reports a distinct optima of $\Delta C_{D}=-0.020$ for a $12^{\circ}$ taper and a slightly smaller reduction of $\Delta C_{D}=-0.018$ at $8^{\circ}$. The differences are within experimental error. The introduction of wheels shows a similar total drag reduction with a shift in the optimum from between $8^{\circ}$ and $12^{\circ}$ to a broader optimum of $12^{\circ}$ to $20^{\circ}$ taper angle. This change in the optimum is not currently understood and is to be the subject of further work.

When introducing an upper taper to the geometry with no wheels only the $4^{\circ}$ case shows any drag reduction; in contrast adding the upper taper to the configuration with wheels results in drag reductions for all taper angles, with an optimum at $12^{\circ}$. It is believed this is due to an optimum drag configuration being present when the wake up-wash and downwash are balanced (as well as a shorter wake [25]). Here this is the case because the shoulder produces a streamwise vortex resulting in an amount of downwash similar to Howell et al. [15], that counteracts the up-wash generated from the rear wheels.

The optimums presented here are expected to change depending on the amount of up-wash that is generated by rear end geometries, such as rear overhang as well as a diffuser. 


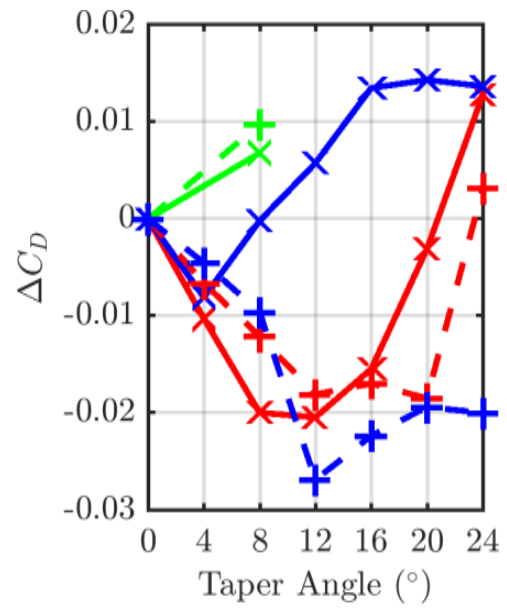

a) $\Delta C_{D}$ for all symmetric taper configurations at $\Psi=0^{\circ}$

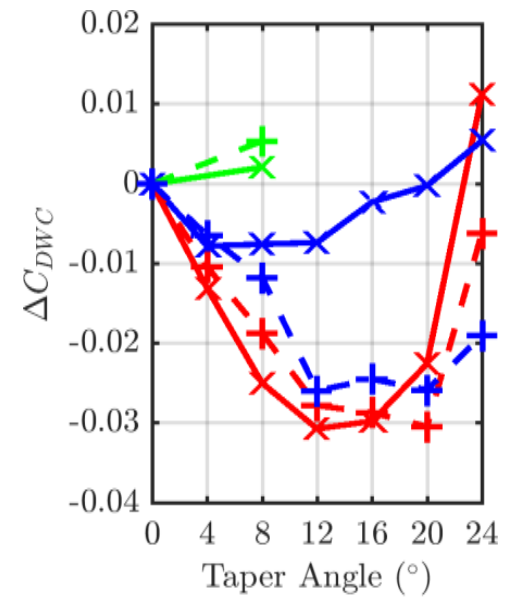

b) $\Delta C_{D W C}$ for all symmetric taper configurations

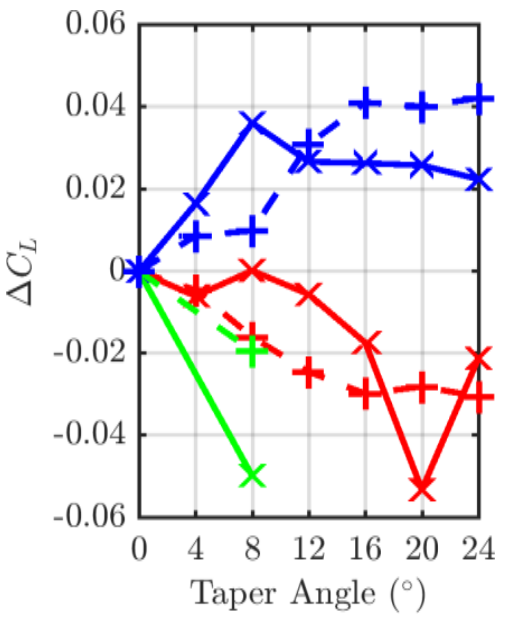

c) $\Delta C_{L}$ for all symmetric taper configurations at $\Psi=0^{\circ}$
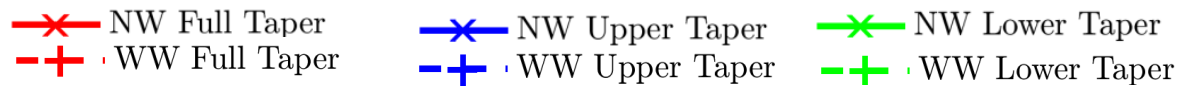

Figure 6. Coefficients for Symmetric Tapering, where $N W$ represents No Wheels and $W W$ represents With Wheels

The wind averaged drag (Equation 5) result is presented for all symmetric tapering in Figure 6b, with the no wheels cases showing a similar trend as Figure 6a, although there is a shift in the optimum taper angle. The variation between the full and upper body taper with wheels is believed to be due to the wheel producing more cross flow and up-wash at yaw than can be counteracted by the shoulder vortex formed by the upper body tapering. The shoulder vortex produces an up-wash only when a lower body taper is considered; this is likely the reason for the drag increase seen both with and without the wheels, producing a more vertically asymmetric wake.

The change in lift on all of the geometries is seen in Figure 6(c) with the upper body taper producing a lift increase and the lower body taper producing a lift reduction. This is partly due to the introduction of an area that is low pressure (as it is adjacent to the tapered surface) that has a positive or negative $\mathrm{z}$-area associated with it. It is also likely that a portion of the change in lift is due to the change in under and over body flow caused by the tapers.

Figure 7 shows the response surfaces of drag (where each point is relative to the respective baseline, such that the $\Delta C_{D}$ value presented at $\Psi=5^{\circ}$ is relative to the baseline geometry at $\Psi=5^{\circ}$ ) of the symmetric full-length tapers at yaw without (a) and with (b) wheels. These plots, combined with the results in Figure 6(b), show that the optimum geometry at $0^{\circ}$ is not the same as the optimal geometry when considering either $\Psi \neq 0^{\circ}$ or a wind averaged drag calculation. The results in Figure 7 suggest that a better drag reduction through a range of yaw values could be achieved if the taper angles were dependent on the aerodynamic yaw of the vehicle and further benefit may be found if these were not symmetrical.
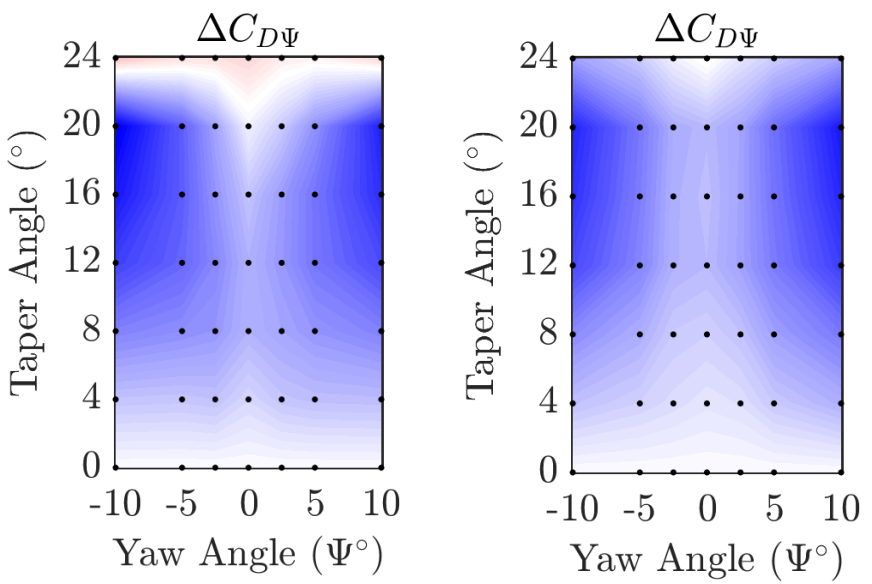

a) No wheels, Full Length Tapers

b) With Wheels, Full Length Tapers

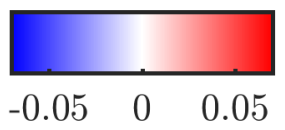

Figure 7. $\Delta C_{D}$ With Respect to $C_{D \Psi}$ for the Respective Baselines 


\section{Asymmetric Tapering}

To reduce the test matrix, an aerodynamic symmetry has been assumed about $0^{\circ}$ yaw, meaning that for a given $\theta_{\text {wind }}$ (windward taper angle) and $\theta_{\text {lee }}$ (leeward taper angle) during the negative portion of the yaw sweep the values can be used for the positive portion of the yaw sweep by swapping the values of $\theta_{\text {wind }}$ and $\theta_{\text {lee }}$. There is also a requirement to modify $C_{Y}, C_{M X}$ and $C_{M Z}$ by changing the sign to make it comparable with the positive yaw values.

The no wheels and full height taper case is presented in detail here as it shows the trends, which are broadly present throughout the geometries, most clearly. The other configurations do show different magnitudes and positions of optima but are not discussed as the maximum and minimum differences can be found in the appendix for all configurations, yaw angles and coefficients. The effect on the cycle averaged drag is considered and discussed.

Figure 8 shows the effect on $\Delta C_{D}$ of changing the leeward and windward taper angle for each of the yaw angles tested, against the baseline value (a-d) and the best symmetric result at each yaw angle (e-h) to better show the change in drag. Figure 8a and Figure 8e show that the optimum at $\Psi=0^{\circ}$ is not a symmetric taper but this is due to the way that $0^{\circ}$ yaw has been chosen (i.e. a fluid dynamic rather than geometric definition).

Figure 8 (a-d) shows that there is a drag benefit from having almost any taper angle over the baseline (squareback) case. Whereas Figure 8 (e-h) shows that there is a drag benefit to having a non-symmetric taper at non-zero yaw conditions, particularly at $\Psi=2.5^{\circ}$.

As the yaw angle moves from $\Psi=0^{\circ}$ the optimum taper angle shifts towards a larger windward taper and smaller leeward taper. This aligns with the trend found by de la Cruz et al. [20] with a similar geometry. They attribute this trend to the re-symmetrising of the wake, shown with a high fluctuation of the lateral pressure on the base of the geometry. Grandemange et al. [26] have shown that the standard deviation of the side force is highest when a geometry has the most symmetric wake. Figure 9, Figure $8 \mathrm{~b}$ and $\mathrm{d}$ show a trend towards larger standard deviations in side force aligning with a larger drag reduction, providing indirect evidence for a link between re-symmetrising the wake and drag reduction.

In Figure 9 around $\theta_{\text {lee }}=24^{\circ}, \theta_{\text {wind }}=20^{\circ}$ there is a region of high standard deviation without significant drag reduction. It is likely due to the separation over the leeward taper which is supported by the same region in Figure 10a showing a reduction in the side force as the taper is no longer providing the suction required to increase the side force.

The trends through larger values of yaw do show a benefit to an asymmetric taper, but the benefit is diminished as a true optimum is not reached. In fact, de la Cruz et al. [20] showed that at a number of yaw angles $\left(\Psi \geq 3^{\circ}\right)$ the optimum value for $\theta_{\text {lee }}$ would most likely be a negative value, such that the taper was protruding from the geometry, but this was not considered in this study.

Figure 11 shows the overall drag reduction for the system if it were adaptive as well as the baseline values and best static symmetric tapers based on $\Delta C_{D W C}$. Without wheels the benefit of an adaptive system over the best static case is $30 \%$ for the full height taper. The upper body tapering results in an improvement of $125 \%$, which is a total of (relative to the baseline) $\Delta C_{D W C}=-0.018$, less than half of the reduction relative to the baseline of the proposed adaptive system with the full height tapering.

Page 5 of 9
When introducing wheels the overall cycle averaged drag reduction is $8 \%$ and $7 \%$ for the full height and the upper body tapering respectively, with the benefit of the adaptive system over the best static cases being $3 \%$ and $19 \%$ respectively.

These drag benefits over both the best static taper and the baseline values are as a result of the specific cycle average drag calculation used. The actual benefit of an adaptive system is dependent on the vehicle it would be applied to and the conditions in which it would be used as some may see no benefit whereas others may see a substantial one. The reductions are not believed to be dependent on high frequency events occurring in a transient environment as Fuller et al. [27] has shown that high frequency events produce little effect on $C_{Y}$ and as a result, $C_{D}$.

Although this system was investigated primarily as a drag reduction device, the cross wind characteristics of the vehicle are also modified. As an example Figure 10 shows the change in the side force, rolling moment and yawing moment coefficients at $\Psi=2.5^{\circ}$ as they are most often associated with cross wind stability. All other coefficients and yaw angles are included in the appendix for completeness.

Typically there is an accelerated flow, resulting in suction, over the tapered surface and the application of asymmetric tapering produces a difference in the pressure between the left (windward) and right hand (leeward) side driving the change in $C_{Y}$. As the tapers are above the origin the same pressure difference drives a change in $C_{M X}$ that is the same sign as the change in $C_{Y}$; in addition, as the tapers are also downstream of the origin $C_{M Z}$ changes with the opposite sign to both $C_{M X}$ and $C_{Y}$. An adaptive system could be implemented to account for the effects of high frequency transient winds on $C_{M Z}$, shown by Fuller et al. [27] to be of no detriment to vehicle performance but a concern for refinement and driver fatigue, and low frequency effects on $C_{Y}$. 


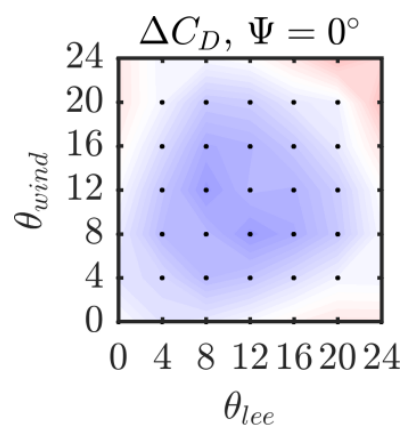

a) $\Psi=0^{\circ}$-Relative to

$\theta_{\text {wind }}=\theta_{\text {lee }}=0^{\circ}$

$\Delta C_{D}$ to $12^{\circ}$

Symmetric Taper,

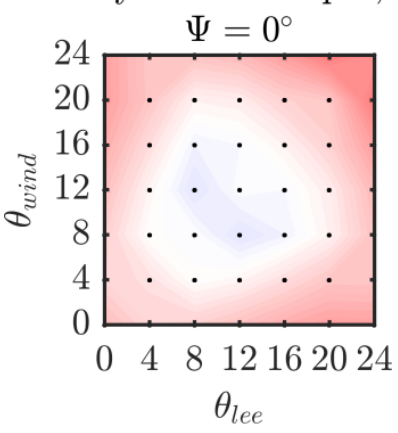

e) $\Psi=0^{\circ}$ - Relative to

$\theta_{\text {wind }}=\theta_{\text {lee }}=12^{\circ}$

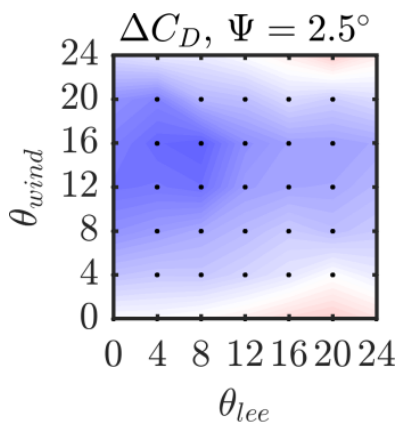

b) $\Psi=2.5^{\circ}$ - Relative to $\theta_{\text {wind }}=\theta_{\text {lee }}=0^{\circ}$

$\Delta C_{D}$ to $12^{\circ}$

Symmetric Taper,

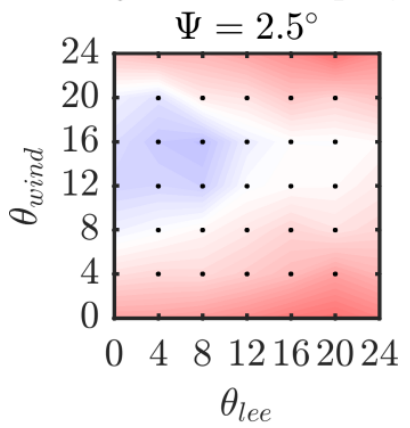

f) $\Psi=2.5^{\circ}$ - Relative to $\theta_{\text {wind }}=\theta_{\text {lee }}=12^{\circ}$

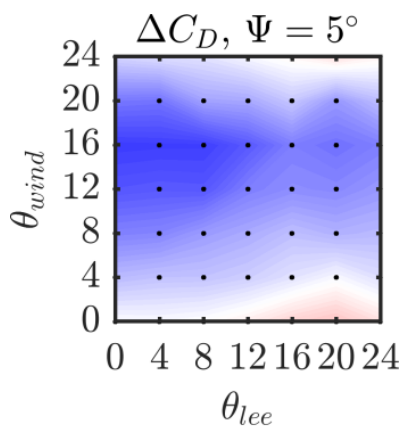

c) $\Psi=5^{\circ}$ - Relative to $\theta_{\text {wind }}=\theta_{\text {lee }}=0^{\circ}$

$\Delta C_{D}$ to $16^{\circ}$

Symmetric Taper,

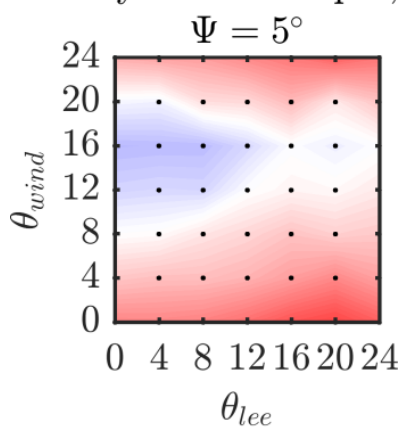

g) $\Psi=5^{\circ}$ - Relative to

$\theta_{\text {wind }}=\theta_{\text {lee }}=16^{\circ}$

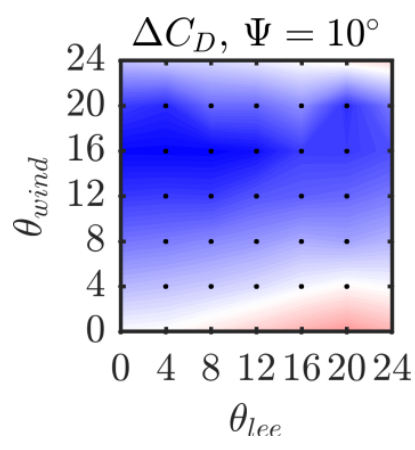

d) $\Psi=10^{\circ}$ - Relative to $\theta_{\text {wind }}=\theta_{\text {lee }}=0^{\circ}$

$\Delta C_{D}$ to $20^{\circ}$

Symmetric Taper,

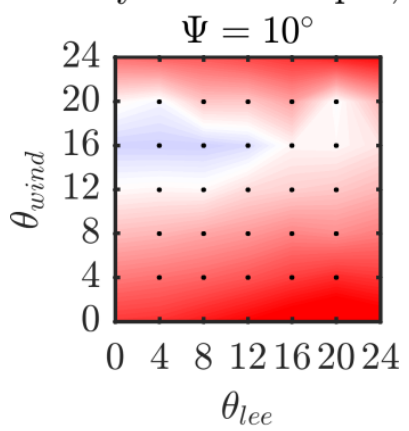

h) $\Psi=10^{\circ}$ - Relative to

$\theta_{\text {wind }}=\theta_{\text {lee }}=20^{\circ}$

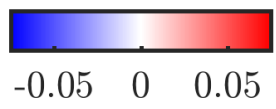

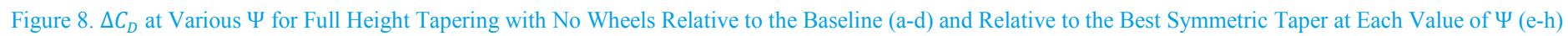

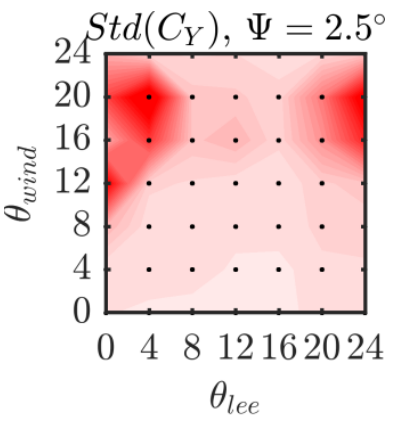

a) $\operatorname{Std}\left(C_{Y}\right)$ at $\Psi=2.5^{\circ}$

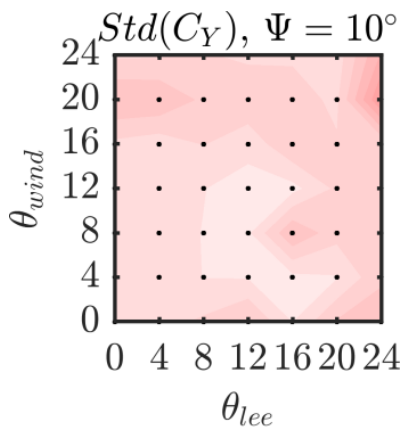

b) $\operatorname{Std}\left(C_{Y}\right)$ at $\Psi=10^{\circ}$

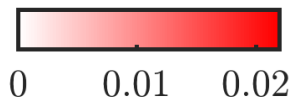

Figure 9. Standard Deviation of Side Force Resampled at $5 \mathrm{~Hz}$ at (a) $\Psi=2.5^{\circ}$ and (b) $\Psi=10^{\circ}$ 


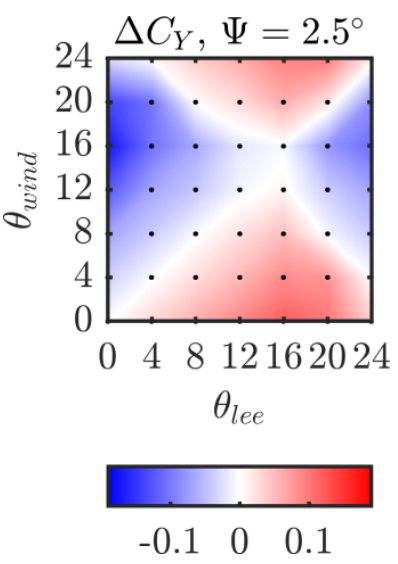

a) $\Delta C_{Y}$
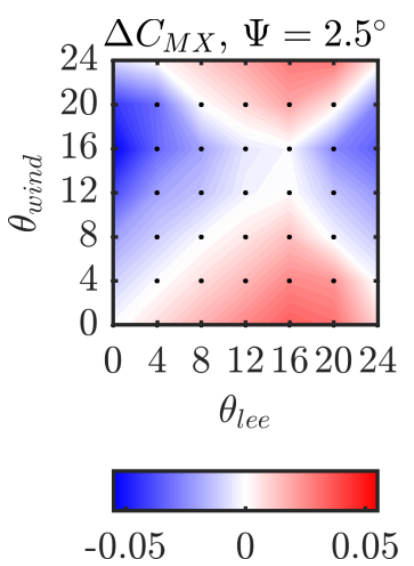
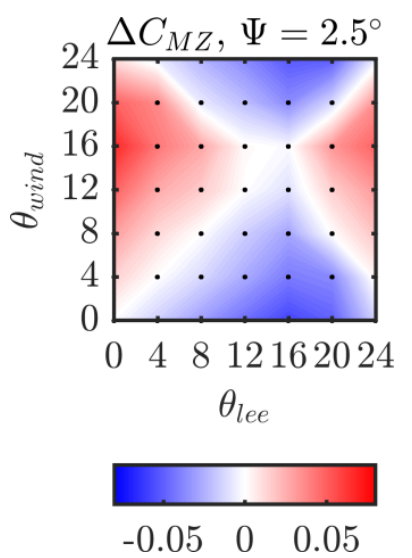

Figure 10. Lateral Coefficients at $\Psi=2.5^{\circ}$ for Full Height Tapering with No Wheels

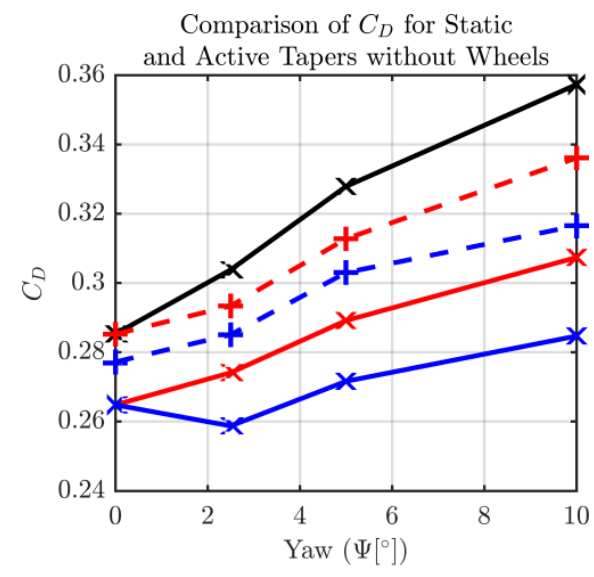

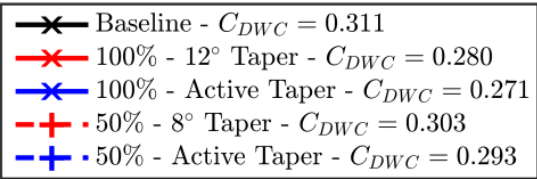

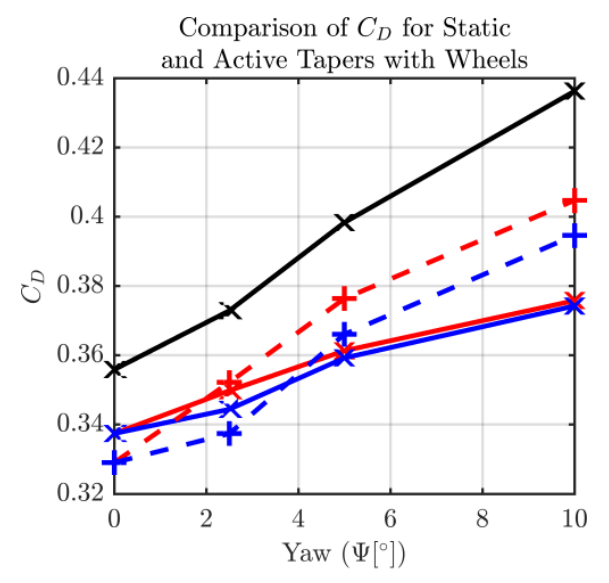

$\longrightarrow$ B Baseline - $C_{D W C}=0.383$

$\rightarrow-100 \%-20^{\circ}$ Taper $-C_{D W C}=0.352$

$\rightarrow-100 \%$ - Active Taper - $C_{D W C}=0.351$

- $-50 \%-12^{\circ}$ Taper $-C_{D W C}=0.357$

-十・50\% - Active Taper - $C_{D W C}=0.352$

Figure 11. A Comparison between Best Case Overall $C_{D W C}$ and the Proposed Active System.

\section{Summary/Conclusions}

The work presented here uses force measurements to investigate the effect of applying asymmetric side edge tapering on a $1 / 4$ scale automotive bluff body of varying complexity.

- $\quad$ Taper optima (at $\Psi=0^{\circ}$ ) are at $4^{\circ}$ and $8^{\circ}-12^{\circ}$ without wheels for the upper body and full body tapers respectively. With wheels the optimum for an upper body taper shifts to $12^{\circ}$ and the full body taper presents a global optimum between $12^{\circ}$ and $20^{\circ}$.

- $\quad$ The wind averaged drag calculation and subsequent results showed a shift in the optimum to higher yaw angles, with a change in the trends of drag reduction from the $\Psi=0^{\circ}$ case.

- For symmetric tapers, the optimum angle is dependent on the yaw angle of the onset flow.
Introducing an asymmetric taper allows the geometry to the optimised for particular yaw angles. If envisaged as a dynamically adjustable (adaptive) system this could allow for a symmetric geometry with the vehicle at rest (or operating in still air) and a drag optimised asymmetric geometry under more typical driving conditions.

- Benefits of the system tested here are centred on small yaw angles $\left(\Psi \cong 2.5^{\circ}\right.$ ) but the benefit could be extended if negative (protruding) taper angles were considered, but was outside the scope of this work.

- At small yaw angles a high fluctuation in the side force, indicative of a symmetric wake, aligned with the low drag configuration, suggesting that the geometries are re-symmetrising the wake to achieve a drag reduction.

- Drag optima were found when the windward taper was larger than the leeward taper, effectively forcing the flow to become more symmetric.

- The best asymmetric geometry showed a drag reduction relative to the best symmetric taper at all non-zero yaw angles. 
- The best symmetric taper drag reductions on each of the configurations are improved with an adaptive asymmetric side taper by $3 \%$ (with wheels and a full height taper) and by $30 \%$ (without wheels and a full height taper).

- The biggest improvement over the best symmetric case is $125 \%$ (without wheels, upper body taper) but is only an additional reduction of -0.010 and does not provide as much overall benefit as the full taper without wheels.

- $\quad$ These geometries modify all of the stability coefficients suggesting that this approach could improve cross wind stability.

Applying this approach to configure an adaptive system on a vehicle could have real benefit in terms of drag reduction with the ability to adapt to any given real-world yaw condition, along with the potential to improve cross wind stability.

\section{Further Work}

Additional work with this drag reduction method is to be centred on how this system affects the base pressure on the model as well as how the system might be controlled.

Initial ideas into controlling the system include an open loop system that measures the pressure upstream of the base on surface susceptible to change with yaw (bumpers, a-pillars) that then use a look up table to find the current yaw angle and the best taper angles for that yaw. Another possibility is a closed loop system with a pair of pressure tapings on the base of the geometry with an aim to minimise the difference between the two, based on the assume symmetry with minimum drag seen here.

\section{References}

1. Brown, Y.A.I., Windsor, S., and Gaylard, A.P., "The Effect of Base Bleed and Rear Cavities on the Drag of an SUV," SAE Technical Paper 2010-01-0512, SAE International, 2010, doi:10.4271/2010-01-0512.

2. Pavia, G., Passmore, M., and Gaylard, A., "Influence of Short Rear End Tapers on the Unsteady Base Pressure of a Simplified Ground Vehicle," SAE Technical Paper 2016-011590, SAE International, 2016, doi:10.4271/2016-01-1590.

3. Perry, A.-K., Passmore, M., and Finney, A., "Influence of Short Rear End tapers on the Base Pressure of a Simplified Vehicle.," SAE Int. J. Passeng. Cars - Mech. Syst. 8:317327, 2015, doi:10.4271/2015-01-1560.

4. Varney, M., Passmore, M., and Gaylard, A., "The Effect of Passive Base Ventilation on the Aerodynamic Drag of a Generic SUV Vehicle," SAE Int. J. Passeng. Cars - Mech. Syst. 10:345-357, 2017, doi:10.4271/2017-01-1548.

5. Howell, J. and Le Good, G., "The Effect of Backlight Aspect Ratio on Vortex and Base Drag for a Simple CarLike Shape," SAE Technical Paper 2008-01-0737, SAE International, 2008, doi:10.4271/2008-01-0737.

6. Grandemange, M., Mary, A., Gohlke, M., and Cadot, O., "Effect on Drag of the Flow Orientation at the Base Separation of a Simplified Blunt Road Vehicle," Exp. Fluids 54(5), 2013, doi:10.1007/s00348-013-1529-z.

7. Ahmed, S.R., Ramm, G., and Faltin, G., "Some Salient Features Of The Time-Averaged Ground Vehicle Wake," SAE Technical Paper 840300, SAE International, 1984, doi: $10.4271 / 840300$.
8. Littlewood, R. and Passmore, M., "The Optimization of Roof Trailing Edge Geometry of a Simple Square-Back.," SAE Technical Paper 2010-01-0510, SAE International, 2010, doi:10.4271/2010-01-0510.

9. Howell, J., Sheppard, A., and Blakemore, A., "Aerodynamic Drag Reduction for a Simple Bluff Body Using Base Bleed," SAE Technical Paper, SAE International, 2003, doi:10.4271/2003-01-0995.

10. Littlewood, R.P. and Passmore, M.A., "Aerodynamic Drag Reduction of a Simplified Squareback Vehicle Using Steady Blowing," Exp. Fluids 53(2):519-529, 2012, doi:10.1007/s00348-012-1306-4.

11. Englar, R.J., Smith, M.J., Niebur, C.S., and Gregory, S.D., "Development of Pneumatic Aerodynamic Concepts for Control of Lift, Drag and Moments plus Lateral/Directional Stability of Automotive Vehicles," SAE Technical Paper, SAE International, 1996, doi:10.4271/960673.

12. Englar, R.J., "Drag Reduction, Safety Enhancement, and Performance Improvement for Heavy Vehicles and SUVs Using Advanced Pneumatic Aerodynamic Technology," SAE Technical Paper, SAE International, ISBN 076801333X, 2003, doi:10.4271/2003-01-3378.

13. Modi, V.J., Fernando, M., and Yokomizo, T., "Moving Surface Boundary-Layer Control as Applied to TwoDimensional and Three-Dimensional Bluff Bodies," J. Wind Eng. Ind. Aerodyn. 38(1):83-92, 1991, doi:10.1016/01676105(91)90029-V.

14. Howell, J., Sims-Williams, D., Sprot, A., Hamlin, F., and Dominy, R., "Bluff Body Drag Reduction with Ventilated Base Cavities," SAE Int. J. Passeng. Cars - Mech. Syst. 2012-01-0171 5:152-160, 2012, doi:10.4271/2012-01-0171.

15. Howell, J., Passmore, M., and Tuplin, S., "Aerodynamic Drag Reduction on a Simple Car-Like Shape with Rear Upper Body Taper," SAE Int. J. Passeng. Cars - Mech. Syst. 6:52-60, 2013, doi:10.4271/2013-01-0462.

16. Stoll, D., Schoenleber, C., Wittmeier, F., Kuthada, T., and Wiedemann, J., "Investigation of Aerodynamic Drag in Turbulent Flow Conditions," 173-187, 2016, doi:10.4271/2016-01-1605.

17. McAuliffe, B.R., Belluz, L., and Belzile, M., "Measurement of the On-Road Turbulence Environment Experienced by Heavy Duty Vehicles," SAE Int. J. Commer. Veh. 7:685702, 2014, doi:10.4271/2014-01-2451.

18. Dalessio, L., Duncan, B., Chang, C., Gargoloff, J.I., and Tate, E., "Accurate Fuel Economy Prediction via a Realistic Wind Averaged Drag Coefficient," SAE Int. J. Passeng. Cars - Mech. Syst. 10(1):2017-01-1535, 2017, doi:10.4271/2017-01-1535.

19. Howell, J., Forbes, D., and Passmore, M., "A drag coefficient for application to the WLTP driving cycle," Proc. Inst. Mech. Eng. Part D J. Automob. Eng. 231(9):1274-1286, 2017, doi:10.1177/0954407017704784.

20. la Cruz, J.M. de, Brackston, R.D., and Morrison, J.F., “Adaptive Base-Flaps Under Variable Cross-Wind," SAE International, 2017.

21. Johl, G., "The Design and Performance of a $1.9 \mathrm{mx} 1.3 \mathrm{~m}$ Indraft Wind Tunnel," Ph.D. thesis, Aeronautical and Automotive Engineering, Loughborough University, 2010.

22. SAE International Vehicle Aerodynamics Terminology, SAE Standard J1594, Rev Dec. 1994.

Page 8 of 9 
23. Carr, G.W. and Stapleford, W.R., "Blockage Effects in Automotive Wind-Tunnel Testing," SAE International Congress and Exposition, SAE International, 1986, doi:10.4271/860093.

24. Coleman, H.W. and Steele, W.G., "Experimentation, validation, and uncertainty analysis for engineers," John Wiley \& Sons, 2009.

25. Pavia, G., Perry, A.K., and Passmore, M., "Influence of Short Rear End Tapers on the Wake of a Simplified SquareBack Vehicle: Wake Topology and Rear Drag," Exp. Fluids 57(11):169, 2016, doi:10.1007/s00348-016-2260-3.

26. Grandemange, M., Cadot, O., Courbois, A., Herbert, V., Ricot, D., Ruiz, T., and Vigneron, R., "A study of wake effects on the drag of Ahmed's squareback model at the industrial scale," J. Wind Eng. Ind. Aerodyn. 145:282-291, 2015, doi:10.1016/j.jweia.2015.03.004.

27. Fuller, J., Best, M., Garret, N., and Passmore, M., "The importance of unsteady aerodynamics to road vehicle dynamics," J. Wind Eng. Ind. Aerodyn. 117:1-10, 2013, doi:10.1016/j.jweia.2013.03.006.

\section{Contact Information}

Max Varney, Stewart Miller Building, Loughborough University, Loughborough, LE1 1 3TU, England. M.Varney@lboro.ac.uk Martin Passmore, M.A.Passmore@lboro.ac.uk

\section{Acknowledgements}

This work was supported by Jaguar Land Rover and the UK EPSRC under an industrial CASE aware (Voucher No. 15220097). Thanks also go to Adrian Gaylard for technical academic support throughout the project as well as the technicians at the university (Nigel Lines, Andrew Horsey and Martin Coleman) for manufacturing the parts and providing mechanical support.

\section{Appendix}

\begin{tabular}{|c|c|c|c|c|c|c|c|}
\hline & \multicolumn{6}{|c|}{ Coefficients } \\
\hline & & $C_{D}$ & $C_{Y}$ & $C_{L}$ & $C_{M X}$ & $C_{M Y}$ & $C_{M Z}$ \\
\hline \multirow{4}{*}{ 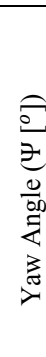 } & 0 & $\begin{array}{l}0.020 / \\
-0.020\end{array}$ & $\begin{array}{l}0.162 / 1 \\
-0.162\end{array}$ & $\begin{array}{l}0.000 / / \\
-0.053\end{array}$ & $\begin{array}{l}0.051 / \\
-0.051\end{array}$ & $\begin{array}{l}0.014 / \\
-0.009\end{array}$ & $\begin{array}{l}0.065 / \\
-0.065\end{array}$ \\
\hline & 2.5 & $\begin{array}{l}0.015 / \\
-0.045\end{array}$ & $\begin{array}{l}0.119 / \\
-0.174\end{array}$ & $\begin{array}{l}0.000 / \\
-0.048\end{array}$ & $\begin{array}{l}0.036 / \\
-0.054\end{array}$ & $\begin{array}{l}0.009 / \\
-0.014\end{array}$ & $\begin{array}{l}0.068 / \\
-0.058\end{array}$ \\
\hline & 5 & $\begin{array}{l}0.019 / \\
-0.056\end{array}$ & $\begin{array}{l}0.116 / \\
-0.131\end{array}$ & $\begin{array}{l}0.000 / \\
-0.046\end{array}$ & $\begin{array}{l}0.035 / \\
-0.039\end{array}$ & $\begin{array}{l}0.009 / \\
-0.020\end{array}$ & $\begin{array}{l}0.060 / \\
-0.059\end{array}$ \\
\hline & 10 & $\begin{array}{l}0.031 / \\
-0.073\end{array}$ & $\begin{array}{l}0.140 / \\
-0.148\end{array}$ & $\begin{array}{l}0.001 / \\
-0.036\end{array}$ & $\begin{array}{l}0.044 / \\
-0.045\end{array}$ & $\begin{array}{l}0.013 / \\
-0.025\end{array}$ & $\begin{array}{l}0.068 / \\
-0.072\end{array}$ \\
\hline
\end{tabular}

Table 2. No Wheels, Full Height Taper Coefficient Ranges

\begin{tabular}{|c|c|c|c|c|c|c|c|}
\hline & \multicolumn{6}{|c|}{ Coefficients } \\
\hline & & $C_{D}$ & $C_{Y}$ & $C_{L}$ & $C_{M X}$ & $C_{M Y}$ & $C_{M Z}$ \\
\hline \multirow{4}{*}{ 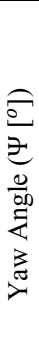 } & 0 & $\begin{array}{l}0.015 / \\
-0.008\end{array}$ & $\begin{array}{l}0.081 / \\
-0.081\end{array}$ & $\begin{array}{l}0.032 / \\
-0.004\end{array}$ & $\begin{array}{l}0.028 / \\
-0.028\end{array}$ & $\begin{array}{l}0.000 / \\
-0.013\end{array}$ & $\begin{array}{l}0.031 / \\
-0.031\end{array}$ \\
\hline & 2.5 & $\begin{array}{l}0.004 / \\
-0.019\end{array}$ & $\begin{array}{l}0.049 / \\
-0.067\end{array}$ & $\begin{array}{l}0.031 / \\
-0.003\end{array}$ & $\begin{array}{l}0.017 / \\
-0.022\end{array}$ & $\begin{array}{l}0.000 / \\
-0.018\end{array}$ & $\begin{array}{l}0.029 / \\
-0.026\end{array}$ \\
\hline & 5 & $\begin{array}{l}0.002 / \\
-0.025\end{array}$ & $\begin{array}{l}0.059 / \\
-0.065\end{array}$ & $\begin{array}{l}0.031 / \\
-0.002\end{array}$ & $\begin{array}{l}0.021 / \\
-0.021\end{array}$ & $\begin{array}{l}0.000 / \\
-0.021\end{array}$ & $\begin{array}{l}0.030 / \\
-0.031\end{array}$ \\
\hline & 10 & $\begin{array}{l}0.008 / \\
-0.041\end{array}$ & $\begin{array}{l}0.064 / \\
-0.078\end{array}$ & $\begin{array}{l}0.034 / \\
-0.004\end{array}$ & $\begin{array}{l}0.023 / \\
-0.027\end{array}$ & $\begin{array}{l}0.000 / \\
-0.029\end{array}$ & $\begin{array}{l}0.037 / \\
-0.034\end{array}$ \\
\hline
\end{tabular}

Table 3. No Wheels, Upper Body Taper Coefficient Ranges

\begin{tabular}{|c|c|c|c|c|c|c|c|}
\hline & \multicolumn{6}{|c|}{ Coefficients } \\
\hline & & $C_{D}$ & $C_{Y}$ & $C_{L}$ & $C_{M X}$ & $C_{M Y}$ & $C_{M Z}$ \\
\hline \multirow{4}{*}{ 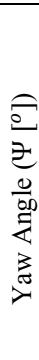 } & 0 & $\begin{array}{l}0.009 / \\
-0.018\end{array}$ & $\begin{array}{l}0.142 / \\
-0.142\end{array}$ & $\begin{array}{l}0.002 / \\
-0.031\end{array}$ & $\begin{array}{l}0.045 / \\
-0.045\end{array}$ & $\begin{array}{l}0.005 / \\
-0.001\end{array}$ & $\begin{array}{l}0.059 / \\
-0.059\end{array}$ \\
\hline & 2.5 & $\begin{array}{l}0.012 / \\
-0.028\end{array}$ & $\begin{array}{l}0.123 / \\
-0.169\end{array}$ & $\begin{array}{l}0.003 / \\
-0.031\end{array}$ & $\begin{array}{l}0.038 / \\
-0.052\end{array}$ & $\begin{array}{c}0.003 / \\
-0.008\end{array}$ & $\begin{array}{l}0.067 / \\
-0.052\end{array}$ \\
\hline & 5 & $\begin{array}{c}0.009 / \\
-0.039\end{array}$ & $\begin{array}{l}0.111 / \\
-0.173\end{array}$ & $\begin{array}{l}0.004 / \\
-0.022\end{array}$ & $\begin{array}{l}0.035 / \\
-0.051\end{array}$ & $\begin{array}{l}0.000 / \\
-0.013\end{array}$ & $\begin{array}{l}0.071 / \\
-0.049\end{array}$ \\
\hline & 10 & $\begin{array}{c}0.019 / \\
-0.062\end{array}$ & $\begin{array}{l}0.113 / \\
-0.187\end{array}$ & $\begin{array}{c}0.007 / \\
-0.020\end{array}$ & $\begin{array}{l}0.035 / \\
-0.056\end{array}$ & $\begin{array}{l}0.005 / \\
-0.023\end{array}$ & $\begin{array}{c}0.080 / \\
-0.049\end{array}$ \\
\hline
\end{tabular}

Table 4. With Wheels, Full Height Taper Coefficient Ranges

\begin{tabular}{|c|c|c|c|c|c|c|c|}
\hline & \multicolumn{6}{|c|}{ Coefficients } \\
\hline & & $C_{D}$ & $C_{Y}$ & $C_{L}$ & $C_{M X}$ & $C_{M Y}$ & $C_{M Z}$ \\
\hline \multirow{4}{*}{ 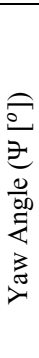 } & 0 & $\begin{array}{l}0.000 / \\
-0.027\end{array}$ & $\begin{array}{c}0.089 / \\
-0.089\end{array}$ & $\begin{array}{l}0.046 / \\
0.000\end{array}$ & $\begin{array}{l}0.028 / \\
-0.028\end{array}$ & $\begin{array}{l}0.000 / \\
-0.024\end{array}$ & $\begin{array}{l}0.034 / \\
-0.034\end{array}$ \\
\hline & 2.5 & $\begin{array}{l}0.004 / \\
-0.035\end{array}$ & $\begin{array}{c}0.080 / \\
-0.093\end{array}$ & $\begin{array}{l}0.041 / \\
0.000\end{array}$ & $\begin{array}{l}0.026 / \\
-0.030\end{array}$ & $\begin{array}{l}0.000 / \\
-0.026\end{array}$ & $\begin{array}{l}0.035 / \\
-0.034\end{array}$ \\
\hline & 5 & $\begin{array}{l}0.001 / \\
-0.032\end{array}$ & $\begin{array}{l}0.076 / \\
-0.091\end{array}$ & $\begin{array}{l}0.019 / \\
-0.005\end{array}$ & $\begin{array}{c}0.026 / \\
-0.029\end{array}$ & $\begin{array}{c}0.000 / \\
-0.019\end{array}$ & $\begin{array}{l}0.037 / \\
-0.034\end{array}$ \\
\hline & 10 & $\begin{array}{l}0.003 / \\
-0.042\end{array}$ & $\begin{array}{c}0.076 / \\
-0.103\end{array}$ & $\begin{array}{l}0.020 / \\
-0.004\end{array}$ & $\begin{array}{l}0.025 / \\
-0.032\end{array}$ & $\begin{array}{l}0.000 / \\
-0.023\end{array}$ & $\begin{array}{l}0.040 / \\
-0.032\end{array}$ \\
\hline
\end{tabular}

Table 5. With Wheels, Upper Body Taper Coefficient Ranges 